\title{
Precipitation microstructure of ultrafine-grained Al-Zn-Mg alloys processed by severe plastic deformation
}

\author{
J. Gubicza ${ }^{1, a}$, I. Schiller ${ }^{1, b}$, N. Q. Chinh ${ }^{2, c}$ and J. Illy ${ }^{2, d}$ \\ ${ }^{1}$ Department of Solid State Physics, Eötvös University, Budapest, P.O.B. 32, H-1518, Hungary \\ ${ }^{2}$ Department of General Physics, Eötvös University, Budapest, P.O.B. 32, H-1518, Hungary

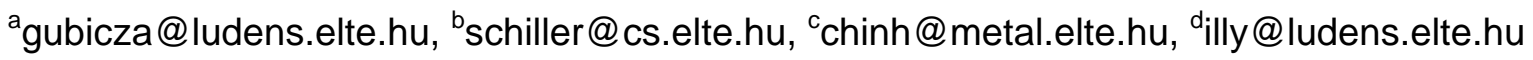

Keywords: Equal Channel Angular Pressing, X-ray diffraction line profile analysis, supersaturated AlZnMg alloys, dislocation density, precipitation.

\begin{abstract}
Supersaturated Al-4.8Zn-1.2Mg-0.14Zr and Al-5.7Zn-1.9Mg-0.35Cu (wt.\%) alloys were processed by Equal-Channel Angular Pressing (ECAP) at $200^{\circ} \mathrm{C}$. The crystallite size distribution and the characteristic parameters of the dislocation structure of both Al matrix and precipitates were determined by X-ray diffraction line profile analysis, which has been complemented by transmission electron microscopy (TEM) observations. Results of these investigations show that the bulk ultrafine-grained microstructure with high dislocation density produced by ECAP has strong influence on the precipitation process, resulting in high strength in both alloys.
\end{abstract}

\section{Introduction}

Severe plastic deformation (SPD) techniques are generally applied for obtaining ultrafine-grained (UFG) microstructure in bulk metals and alloys [1]. Equal-Channel Angular Pressing (ECAP) is the most often used method among SPD procedures since it results in homogeneous UFG microstructure without contamination and changing the dimensions of the bulk specimen [2-4]. For understanding the mechanical behavior of materials produced by ECAP it is necessary to characterize their microstructure.

X-ray diffraction line profile analysis is an effective tool for studying the microstructure of UFG materials. Both the small crystallite size and the long-range strain fields of the lattice defects cause broadening of line profiles. In SPD processed materials, where the lattice distortions are primarily caused by dislocations, the strain broadening of the line profiles can be expressed in terms of the characteristic parameters of the dislocation structure [5-8]. In the last few years, a fast development in computing made it possible to work out procedures for determining the parameters of the microstructure by fitting the whole diffraction profiles [9-11]. In the recently elaborated Multiple Whole Profile (MWP) fitting method, the measured intensity profiles or their Fourier transforms are fitted by theoretical functions calculated on the basis of a model of the microstructure [10,11]. This procedure enables to determine both the crystallite size distribution and the dislocation structure in UFG materials.

In this study the microstructure of Al-4.8Zn-1.2Mg-0.14Zr and Al-5.7Zn-1.9Mg-0.35Cu (wt.\%) alloys processed by ECAP deformation at $200^{\circ} \mathrm{C}$ is investigated. The crystallite size distribution and the parameters of the dislocation structure for both the matrix and the precipitates are determined by X-ray diffraction line profile analysis. The morphology, the size and the dispersion of precipitates are studied by transmission electron microscopy (TEM). Furthermore, the yield strength is correlated to the characteristic parameters of microstructure. 


\section{Experimentals}

Billets of Al-4.8Zn-1.2Mg-0.14Zr and Al-5.7Zn-1.9Mg- $0.35 \mathrm{Cu}$ (wt.\%) alloys were processed by ECAP. Before ECAP processing, the material was subjected to solute heat treatment at $470{ }^{\circ} \mathrm{C}$ for 30 minutes and water-quenched, resulting in supersaturated solid solution. Cylindrical billets of 10 $\mathrm{mm}$ in diameter and $70 \mathrm{~mm}$ in length were pressed through the ECAP die with $90^{\circ}$ intersecting channels. Eight passes were performed following route $\mathrm{B}_{\mathrm{C}}$ (the billet was rotated around its longitudinal axis by $90^{\circ}$ between intermediate passes) at constant displacement rate of $5 \mathrm{~mm} / \mathrm{s}$. The ECAP procedure was carried out at $200^{\circ} \mathrm{C}$ because at low temperatures the high rigidity of the specimens results in crack formation and breaking of the billets. Owing to the relatively high temperature of ECAP, precipitates are formed from the supersaturated solid solution. Several important mechanical and precipitation properties of these alloys after quenching have been reported before [12-15].

The phase composition of the specimens was determined by X-ray diffraction using a Philips $\mathrm{X}$ 'pert powder diffractometer with a $\mathrm{Cu}$ anode. For studying the microstructure, the X-ray line profiles of both the Al matrix and the precipitates were measured on the cross section of the billets after the last ECAP pass by a high-resolution double-crystal diffractometer (Nonius, FR 591) using $\mathrm{Cu} \mathrm{K} \alpha_{1}$ radiation. The peak profiles were evaluated by the Multiple Whole Profile (MWP) fitting procedure described in details in Refs. [10,11]. In this method, the Fourier coefficients of the experimental profiles are fitted by the product of the theoretical Fourier transforms of size and strain peak profiles. The theoretical functions used in this fitting procedure are calculated on the basis of a model of the microstructure, where the crystallites have spherical shape and log-normal size distribution, and the lattice strains are assumed to be caused by dislocations. The method gives the area-weighted mean crystallite size $(\varangle x>$ area $)$, the density $(\rho)$, the character $(q)$ and the arrangement of dislocations $(M)$ for the ECAP processed specimens.

The microstructure was also investigated by a JEOL-200CX transmission electron microscope (TEM) operating at $200 \mathrm{kV}$. The TEM foils were taken from the centre of the cross section perpendicular to the axis of the output channel of the last ECAP pass. The yield strength of the specimens was determined as one-third of the hardness measured on the cross section of the billets by Vickers indentation.

\section{Results and discussion}

Figure 1 shows the X-ray diffraction pattern taken on the cross section of the Al-5.7Zn-1.9Mg$0.35 \mathrm{Cu}$ specimen processed by $8 \mathrm{ECAP}$ passes. Beside the strong peaks (denoted by open circles in Fig.1) corresponding to the reflections of the Al matrix, several weaker peaks (denoted by solid squares in Fig.1) were also observed indicating the existence of $\mathrm{MgZn}_{2}$ precipitates ( $\eta$ phase). These particles were formed from the supersaturated solid solution during high temperature ECAP. The $\eta$ precipitates develop usually during ageing from the Guinier-Preston (GP) zones through the intermediate $\eta$ ' phase $[16,17]$. The particles of $\eta$ phase are regarded as incoherent precipitates in the Al matrix, contrary to the coherent GP zones and $\eta$ ' phase $[16,17]$.

Figure 2 shows the 111/222 pair of X-ray line profiles of the Al matrix and the 002/004 reflections of $\mathrm{MgZn}_{2}$ precipitates for the Al-5.7Zn-1.9Mg- $0.35 \mathrm{Cu}$ specimen processed by 8 ECAP passes. The higher width of 222 reflection compared to 111 peak indicates the existence of strain broadening of the profiles for Al matrix. At the same time the 002 and 004 reflections of $\mathrm{MgZn}_{2}$ phase are practically the same, indicating that the strain broadening of the line profiles for $\eta$ precipitates is negligible. This can be explained by the incoherency of $\eta$ particles with the matrix so that the dislocations do not cut through precipitates but they are moving around the $\eta$ particles (bypass mechanism). 


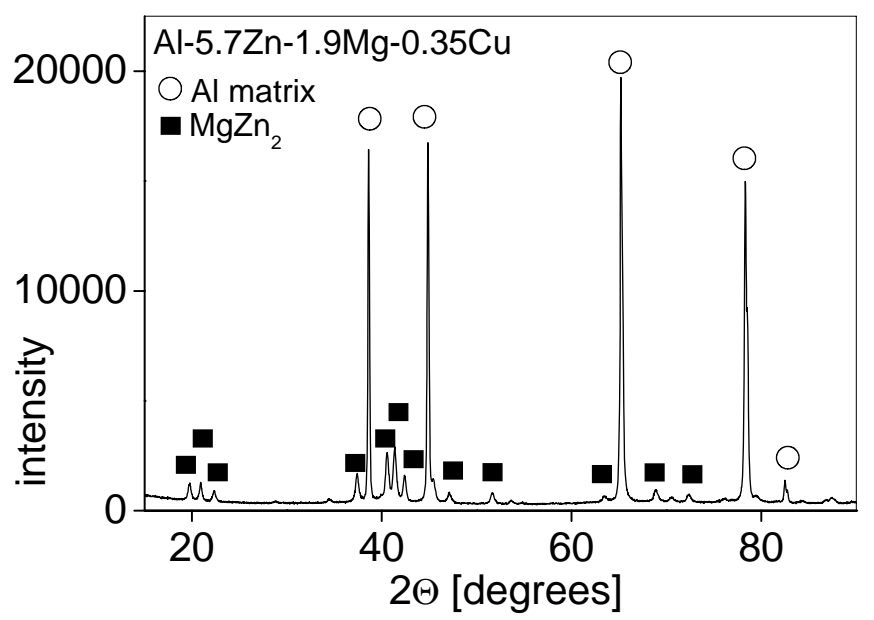

Figure 1: The X-ray diffractogram for the Al-5.7Zn-1.9Mg-0.35Cu specimen processed by ECAP.

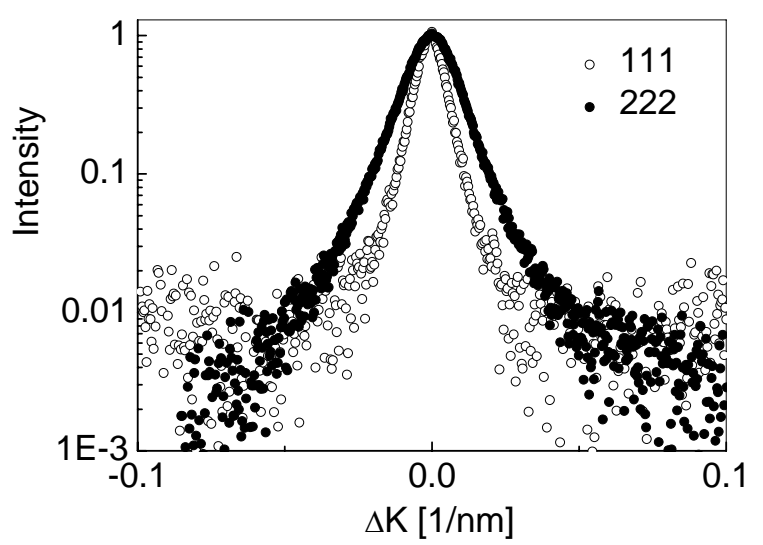

a)

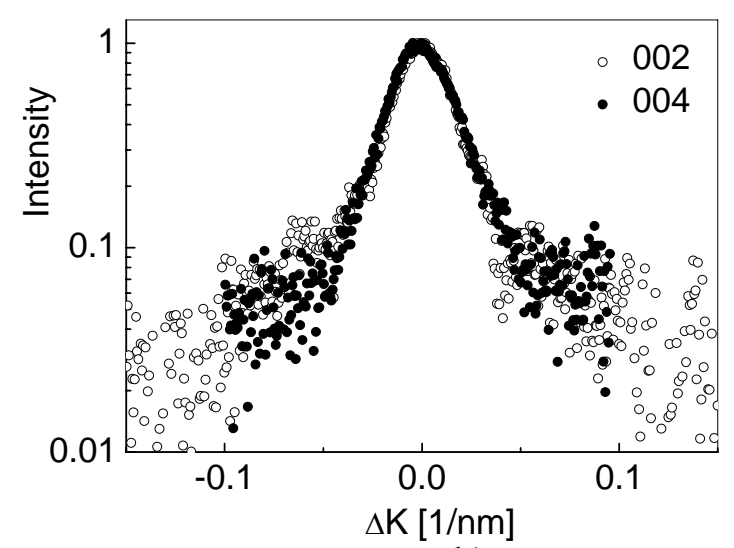

b)

Figure 2: The 111/222 pair of X-ray line profiles of the Al matrix (a) and 002/004 reflections of $\mathrm{MgZn}_{2}$ precipitates (b) for the Al-5.7Zn-1.9Mg-0.35Cu specimen processed by 8 ECAP passes.

The line profiles of both the Al matrix and $\eta$ precipitates were evaluated by MWP fitting procedure. Fig. 3 shows, for instance, the Fourier coefficients of the measured intensity profiles (open circles) and the fitted theoretical Fourier transforms (solid line) for the Al matrix of Al$5.7 \mathrm{Zn}-1.9 \mathrm{Mg}-0.35 \mathrm{Cu}$ specimen processed by ECAP. The difference between the measured and fitted values is also plotted in the figure. As the results of the fitting procedure, the area-weighted mean crystallite size of $165 \pm 15$ and $119 \pm 14 \mathrm{~nm}$ were obtained for the matrices of the Al-4.8Zn$1.2 \mathrm{Mg}-0.14 \mathrm{Zr}$ and $\mathrm{Al}-5.7 \mathrm{Zn}-1.9 \mathrm{Mg}-0.35 \mathrm{Cu}$ alloys, respectively. The evaluated values of the dislocation density are $3.2 \pm 0.4 \times 10^{14}$ and $3.4 \pm 0.4 \times 10^{14} \mathrm{~m}^{-2}$ whereas the $q$ parameter describing the edge/screw character of dislocations are $0.61 \pm 0.07$ and $0.57 \pm 0.07$ for the Al-4.8Zn-1.2Mg- $0.14 \mathrm{Zr}$ and $\mathrm{Al}-5.7 \mathrm{Zn}-1.9 \mathrm{Mg}-0.35 \mathrm{Cu}$ alloys, respectively. Assuming the $<110>\{111\}$ slip system, the theoretical values of the $q$ parameter for pure screw and edge dislocations in the aluminium matrix are 1.33 or 0.36 , respectively [18]. The experimental values of the $q$ parameters for the two alloys are slightly lower than the arithmetic average $(0.85)$ of the theoretical values for pure edge and screw dislocations indicating that the character of the dislocation structure is rather edge than screw. The dimensionless dislocation arrangement parameter, $M$, has a value of $2.1 \pm 0.3$ and $3.3 \pm 0.3$ for the Al-4.8Zn-1.2Mg-0.14Zr and Al-5.7Zn-1.9Mg-0.35Cu alloys, respectively. The smaller value 
of $M$ shows stronger dipole character of the dislocation structure. Because of the negligible strain broadening of their line profiles, the dislocation structure of the precipitates was not evaluated from the diffraction peaks. The area-weighted mean crystallite size obtained from the line profile analysis for the precipitates in the Al-4.8Zn-1.2Mg-0.14Zr and Al-5.7Zn-1.9Mg-0.35Cu alloys are 30 and 22 nm, respectively.

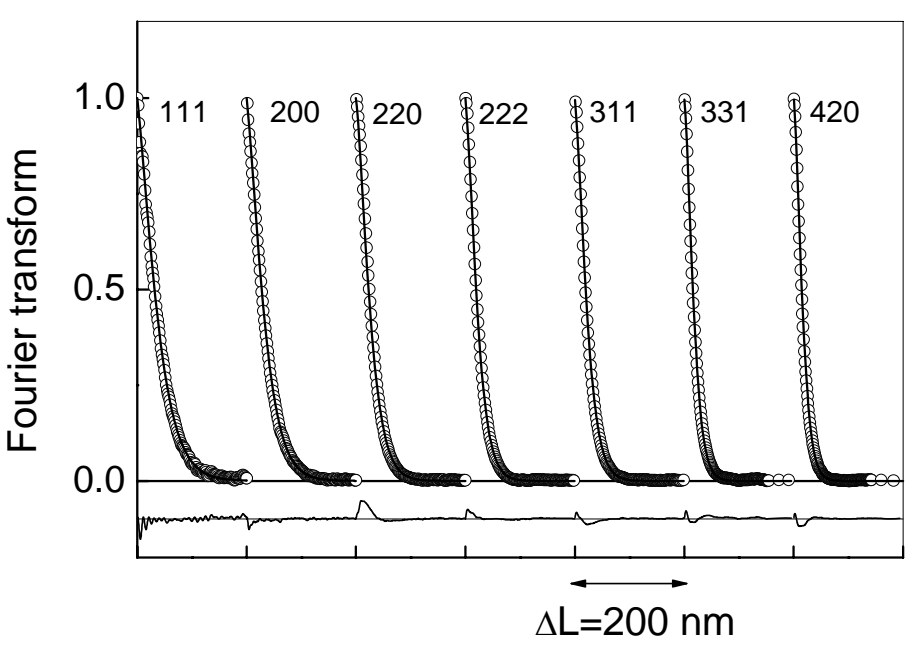

Figure 3: The Fourier coefficients of the measured intensity profiles (open circles) and the fitted theoretical Fourier transforms (solid line) for the Al matrix of the Al-5.7Zn-1.9Mg-0.35Cu specimen processed by 8 ECAP passes.

Figure 4 shows TEM micrographs on the microstructure of both alloys after ECAP. The grain size of the matrix for the Al-4.8Zn-1.2Mg-0.14Zr and Al-5.7Zn-1.9Mg-0.35Cu alloys determined from the TEM images are 500 and $300 \mathrm{~nm}$, respectively, which are 2.5-3 times higher than the values obtained from X-ray analysis. This is a general observation because of the subgrain-structure of the grains for metals processed by SPD techniques. The crystallite size determined from X-ray line profiles corresponds rather to the size of subgrains or dislocation cells which is smaller than the grain size observable in TEM micrographs $[10,19]$. The average size of the precipitates in the Al$4.8 \mathrm{Zn}-1.2 \mathrm{Mg}-0.14 \mathrm{Zr}$ and $\mathrm{Al}-5.7 \mathrm{Zn}-1.9 \mathrm{Mg}-0.35 \mathrm{Cu}$ alloys obtained from the images are 30 and 20 $\mathrm{nm}$, respectively. These values are in good agreement with those determined by line profile analysis, confirming that the $\mathrm{MgZn}_{2}$ particles are single crystals, i.e.- contrary to the grains of the matrix - they have no subgrain-structure. The average distance, $D$ between the precipitates is approximately $120 \mathrm{~nm}$ in the Al-4.8Zn-1.2Mg-0.14Zr alloy and $80 \mathrm{~nm}$ in the Al-5.7Zn-1.9Mg$0.35 \mathrm{Cu}$ alloy. The experimental results show that the precipitates in the $\mathrm{Cu}$-containing alloy have smaller size and finer dispersion, than in the other alloy. This difference is a consequence of the different alloying composition of the two specimens. The higher concentration of the alloying elements and especially the $\mathrm{Cu}$ addition hinder the coarsening of precipitates [20]. Furthermore, it has also been shown before that the addition of $\mathrm{Cu}$ into AlZnMg alloys, in the one hand, increases the upper temperature of GP zone- $\eta$ ' phase transition, and on the other hand, increases the density of GP zones [12,15], which have a strong influence on the formation of $\eta$ ' particles, leading to finer dispersion of $\eta$ precipitates.

Considering the strengthening effect of non-cutable particles, such as $\eta$ phase precipitates, it is well known that both the decreasing particle-distance $(D)$ and increasing precipitate-size $(\mathrm{x})$ increase the hindering effect of the particles on the movement of dislocations [21]. The effect of particle-distance is, however, stronger than that of precipitate-size. In the present investigation, as both the average size of precipitates and the distance between the $\eta$ particles in the Al-5.7Zn$1.9 \mathrm{Mg}-0.35 \mathrm{Cu}$ alloy is lower than that obtained for the $\mathrm{Al}-4.8 \mathrm{Zn}-1.2 \mathrm{Mg}-0.14 \mathrm{Zr}$ alloy by the same 
factor (2/3), the precipitate structure of the Cu-containing alloy has higher hindering effect on dislocation motion, resulting in lower recovery rate during high temperature ECAP process. This is the reason why smaller crystallite and grain sizes, as well as weaker dipole character of the dislocation structure were obtained in the $\mathrm{Al}-5.7 \mathrm{Zn}-1.9 \mathrm{Mg}-0.35 \mathrm{Cu}$ alloy.
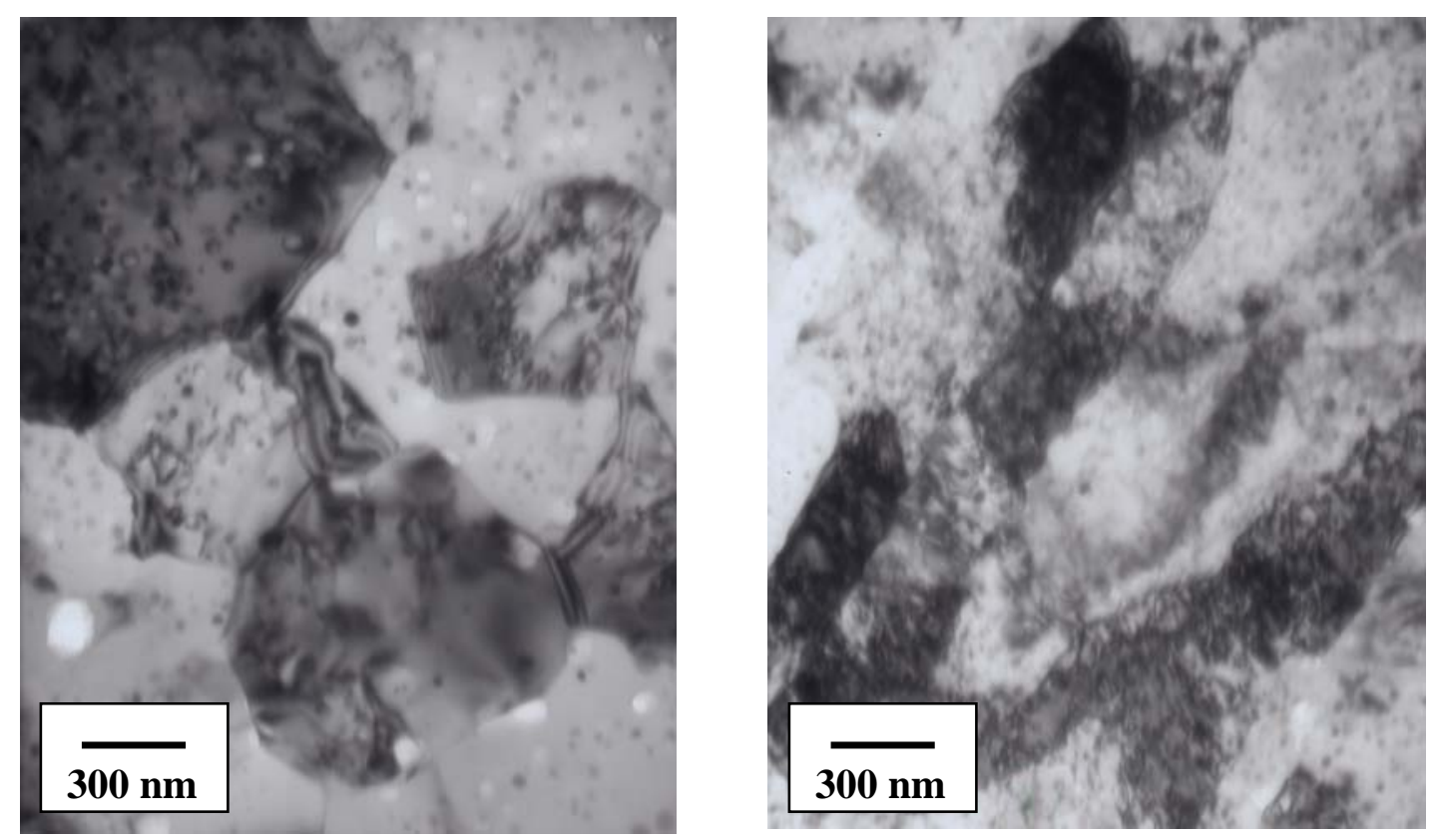

Figure 4: TEM micrographs for the specimens Al-4.8Zn-1.2Mg-0.14Zr (left) and Al-5.7Zn-1.9Mg-0.35Cu (right) processed by 8 ECAP passes.

It should be mentioned that the dislocation density $\left(3.4 \pm 0.4 \times 10^{14} \mathrm{~m}^{-2}\right)$ in the Cu-containing alloy in the present work is the same as the value obtained by Zhao et al. [22] for a commercial $\mathrm{AlZnMgCu}$ (7075) alloy, which was, however, processed by ECAP at room temperature (RT), then naturally aged at RT for 30 days and finally artificially aged up to $200^{\circ} \mathrm{C}$ separately in a calorimeter. This way of the formation of precipitates essentially differs from our procedure where the ECAP was carried out at $200^{\circ} \mathrm{C}$. In spite of the same dislocation density formed in both cases, the precipitation process - the shape of $\eta$ phase particles - seems to be influenced by the processing route. Zhao et al. have observed needle-like precipitates after subsequent ECAP at RT and ageing at $200^{\circ} \mathrm{C}$, while in our experiments only spherical particles were formed during ECAP at $200^{\circ} \mathrm{C}$. According to the recently reported results [15] the addition of $\mathrm{Cu}$ into AlZnMg alloys results in both spherical and ellipsoidal GP zones and $\eta$ ' precipitates so that the spherical particles are practically $\mathrm{Cu}$-free, while the ellipsoidal ones contain a significant amount of $\mathrm{Cu}$ atoms. This is the reason of the observation of both spherical and needle-like precipitates after the mentioned statistic ageing of Zhao et al., if taking into account the GP zone $\rightarrow \eta \cdot \rightarrow \eta$ subsequences. In our experiments the lack of needle-like particles is certainly the consequence of the dynamic ageing process. It can be supposed that the $\eta$ ' phase nucleus, which can be formed in the early stage, during the first pass of ECAP process at $200^{\circ} \mathrm{C}$, are sheared and cut by dislocations introduced by severe plastic deformation. The $\eta$ ' phase precipitates formed mainly along $\{110\}$ planes and then cut by dislocations along the most active $\{111\}$ planes may be divided into smaller particles, leading to the formation of smaller and rather spherical $\eta$ phase precipitates during subsequent ECAP at $200^{\circ} \mathrm{C}$. 
Concerning the strength of particle-hardened ultrafine-grained Al alloys different strengthening mechanisms should be considered. These are i) work hardening process, i.e. the interaction between dislocations in the grain interiors of the matrix, ii) Hall-Petch effect, i.e. the interaction between dislocation and grain boundary, iii) solid solution hardening and iv) precipitation strengthening [23]. The first three effects occur if the alloy is solid solution while the fourth one should be taken into account additionally if the material contains precipitations. Recently, it has been shown [24] for both pure Al and Al-Mg solid solutions processed by ECAP at room temperature that the yield strength $\left(\sigma_{y}\right)$ measured by mechanical tests agreed well with the strength values calculated from the dislocation density using the well-known Taylor-equation:

$$
\sigma_{y}=\sigma_{0}+\alpha M^{T} G b \rho^{1 / 2}
$$

where $\sigma_{0}$ is the friction stress, $\alpha$ is a constant ( $\alpha=0.33$ is taken), $G$ is the shear modulus ( $G=26$ $\mathrm{GPa}), b$ is the length of the Burgers vector of dislocations $(b=0.2865 \mathrm{~nm})$ and $M^{T}$ is the Taylor factor $\left(M^{T}=3\right.$ for untextured polycrystalline materials). This result suggests that for ultrafine-grained $\mathrm{Al}$ alloys processed by SPD, the interaction between the dislocations (work hardening), as well as the effects of the grain boundaries (Hall-Petch) and of the solute atoms (solid solution hardening) on the strength can be incorporated into the average dislocation density, $\rho$. For the effect of the grain boundaries, this observation can be explained by the fact that in the materials processed by SPD, the grain refinement occurs by the arrangement of dislocations into subgrain-boundaries and/or dislocation walls. Consequently, the majority of boundaries consist of dislocations and the effect of subgrain/grain boundaries on the dislocation motion can be regarded as the interaction between dislocations [25]. Concerning the solid solution strengthening, the solute atoms may increase the strength in two ways: i) directly by pinning the dislocations and impeding their motion (solute-dislocation interaction) and ii) indirectly by hindering the annihilation of dislocations during deformation, leading to an increase in the dislocation density (dislocation-dislocation interaction). For severely deformed metals, where the dislocation density is relatively high, the latter factor is the dominant, i.e. the hardening effect of solute atoms is manifested basically in the higher dislocation density.

In the alloys investigated here, beside the strengthening effect of dislocations, the precipitatehardening should be also considered. Assuming the additivity of the different strengthening contributions, the yield strength can be given by the following formula [26]:

$$
\sigma_{y}=\sigma_{0}+\alpha M^{T} G b \rho^{1 / 2}+0.85 M^{T} \frac{G b \ln (x / b)}{2 \pi(D-x)},
$$

where $x$ is the average size of precipitates. The different contrbutions to yield strength was calculated from Eq. 2 using the values of $D$ and $x$ obtained from TEM micrographs and the dislocation density determined by line profile analysis. The value of $\sigma_{0}$ is taken as $20 \mathrm{MPa}$ measured for pure Al [27], as the lattice parameter of the matrix obtained from the X-ray diffractograms agrees with the value for pure Al within the experimental error. The strength contributions originated from the dislocation density (second term in Eq. 2) are 133 and $137 \mathrm{MPa}$ for $\mathrm{Al}-4.8 \mathrm{Zn}-1.2 \mathrm{Mg}-0.14 \mathrm{Zr}$ and $\mathrm{Al}-5.7 \mathrm{Zn}-1.9 \mathrm{Mg}-0.35 \mathrm{Cu}$ alloys, respectively, as the dislocation densities in the two matrix are close to each other. The third term in Eq. 2 caused by the dislocation-precipitation interaction gives 156 and $214 \mathrm{MPa}$ for Al-4.8Zn-1.2Mg-0.14Zr and Al$5.7 \mathrm{Zn}-1.9 \mathrm{Mg}-0.35 \mathrm{Cu}$ alloys, respectively. The difference between the two values is resulted by the different size and dispersion of precipitates. The smaller particles with more dense distribution causes higher strength for Al-5.7Zn- $1.9 \mathrm{Mg}-0.35 \mathrm{Cu}$ alloy. The sum of the three components gives the total strength of $309 \pm 20$ and $371 \pm 25 \mathrm{MPa}$ which are in good agreement with the values 
determined by mechanical test $(290 \pm 10$ and $350 \pm 10 \mathrm{MPa})$ for Al-4.8Zn-1.2Mg-0.14Zr and Al$5.7 \mathrm{Zn}-1.9 \mathrm{Mg}-0.35 \mathrm{Cu}$ alloys, respectively.

\section{Summary}

High temperature $\left(200^{\circ} \mathrm{C}\right)$ ECAP technique was applied to produce ultrafine-grained microstructure in $\mathrm{Al}-4.8 \mathrm{Zn}-1.2 \mathrm{Mg}-0.14 \mathrm{Zr}$ and $\mathrm{Al}-5.7 \mathrm{Zn}-1.9 \mathrm{Mg}-0.35 \mathrm{Cu}$ alloys. The high temperature deformation resulted in the formation of $\mathrm{MgZn}_{2}(\eta)$ precipitates from the supersaturated solid solution. The parameters of the microstructure for both the Al matrix and the precipitates were detemined by Xray line profile analysis. It was found that the strain broadening of the line profiles for $\eta$ precipitates is negligible. This indicates that the dislocations do not cut through precipitates which can be explained by the incoherency of $\eta$ particles with the matrix. The Al-5.7Zn-1.9Mg- $0.35 \mathrm{Cu}$ alloy contains smaller $\mathrm{MgZn}_{2}$ particles with lower distance between them compared to Al-4.8Zn-1.2Mg$0.14 \mathrm{Zr}$ which results in higher strength in the former alloy. It was also shown that the yield strength calculated from the dislocation density, the size and distance of precipitates was in good agreement with the values determined by mechanical test.

\section{Acknowledgements}

This work was supported by the Hungarian Scientific Research Fund, OTKA, Grant Nos. F-047057, T-043247 and T-038048.

\section{References}

[1] R.Z. Valiev, R.K. Islamgaliev, I.V. Alexandrov, Prog. Mater. Sci. Vol. 45 (2000), p. 103.

[2] Y. Iwahashi, Z. Horita, M. Nemoto and T.G. Langdon: Metall. Mater. Trans. A Vol. 29A (1998), p. 2503.

[3] V.V. Stolyarov, Y.T. Zhu, I.V. Alexandrov, T.C. Lowe and R.Z. Valiev: Mater. Sci. Eng. A Vol. 303 (2001), p. 82.

[4] A. Dubravina, M.J. Zehetbauer, E. Schafler, I.V. Alexandrov, Mater. Sci. Eng. A Vol. 387-389 (2004), p. 817.

[5] M.A. Krivoglaz: Theory of X-ray and Thermal Neutron Scattering by Real Crystals (Plenum Press, New York 1996).

[6] M. Wilkens: Phys. Stat. Sol. (a) Vol. 2 (1970), p. 359

[7] R. Kuzel jr. and P. Klimanek: J. Appl. Cryst. Vol. 21 (1988), p. 363

[8] E. Schafler and R. Pippan: Mater. Sci. Eng. A Vol. 387-389 (2004) p. 799.

[9] P. Scardi and M. Leoni: Acta Cryst. A Vol. 58 (2002), p. 190

[10] T. Ungár, J. Gubicza, G. Ribárik and A. Borbély: J. Appl. Cryst. Vol. 34 (2001), p. 298

[11] G. Ribárik, T. Ungár and J. Gubicza: J. Appl. Cryst. Vol. 34 (2001), p. 669.

[12] N. Q. Chinh, Zs. Kovács, L. Reich, F. Székely, J. Illy and J. Lendvai: Z. Metallk.Vol. 88 (1997), p. 607.

[13] N. Q. Chinh, F. Csikor and J. Lendvai: Mater. Sci. Forum Vol. 332 (2000), p. 1007.

[14] N. Q. Chinh, Gy. Horváth, Zs. Kovács and J. Lendvai: Mater. Sci. Eng. A324 (2002), p. 219.

[15] N. Q. Chinh, J. Lendvai, D. H. Ping and K. Hono: J. All. Comp. Vol. 378 (2004), p. 52. 
[16] J. Q. Su, T. W. Nelson, R. Mishra and M. Mahoney: Acta Mater. Vol. 51 (2003), p. 713.

[17] L. F. Mondolfo, Int. Metall. Rev. 153 (1971), 95.

[18] J. Gubicza, M. Kassem, G. Ribárik and T. Ungár: Mater. Sci. Eng. A Vol. 372 (2004), p. 115.

[19] J. Gubicza, N.Q. Chinh, Z. Horita and T.G. Langdon: Mater. Sci. Eng. A Vol. 387-389 (2004), p. 55.

[20] T. Engdahl, V. Hansen, P. J. Warren and K. Stiller: Mater. Sci. Eng. A Vol. 327 (2002), p. 59.

[21] M. F. Ashby: Proc. Second Bolton Landing Conference on Oxide Dispersion Strenghtening (Gordon and Breach, New York 1968) pp. 119.

[22] Y.H. Zhao, X.Z. Liao, Z. Jin, R.Z. Valiev and Y.T. Zhu: Acta Mater. Vol. 52 (2004), p. 4589.

[23] M. J. Starink and S. C. Wang: Acta Mater., Vol. 51 (2003), p. 5131.

[24] J. Gubicza, N. Q. Chinh, Gy. Krállics, I. Schiller and T. Ungár: Curr. Appl. Phys. Vol. 6 (2006), p. 194.

[25] D.A. Hughes and N. Hansen: Acta Mater. Vol. 48 (2000), p. 2985.

[26] U. F. Kocks: Phil. Mag. Vol. 13 (1966), p. 541.

[27] N. Q. Chinh, Gy. Horváth, Z. Horita and T. G. Langdon: Acta Mater. Vol. 52 (2004), p. 3555. 